\title{
A Quantitative Analysis of Radiation-Induced Chromosome Aberrations with a Fluorescent Digital Image Microscope
}

\author{
YOSUKE KAMEOKA, MAKOTO HIRATA, EISUKE GOTO, \\ LI RONG DENG, HIDEAKI MAEKAWA, \\ AND KATSUYUKI HASHIMOTO
}

\author{
National Institute of Health, 10-35, Kamiosaki 2-chome, \\ Shinagawa-ku, Tokyo 141, Japan
}

chromosome aberration/dicentrics/alpha satellite DNA/fluorescence in situ hybridization/fluorescence digital image microscope

Using a synthetic, alpha satellite consensus DNA unit as a probe, we could show dicentrics as well as acentric fragmented chromosomes in metaphases of $\gamma$-irradiated lymphocyte cells and that the number of appearance of dicentrics or acentric fragments seemed to be proportional to radiation doses. To make such examination with a large number of chromosomes of metaphases, a quantitative fluorescence measurement was performed using a fiuorescent microscope digital image analysis system.

The relative amounts of fluoresceinated probe hybridized to alpha satellite DNA varied with chromosomes to a certain extent (1-4\% of total probe-fluorescence of one metaphase). However, we could score dicentrics and acentric fragments as dots with extraordinarily higher or low percentage in plots of relative amount of probe-fluorescence on metaphase chromosome in $\gamma$-irradiated cells. The number of appearacne of acentric fragments were proportional to radiation doses of 1,2 and $4 \mathrm{~Gy}$. In the case of dicentrics, the number of appearance seemed to be proportional to square doses. Further, to reduce the variation of relative amounts of probe-fluorescence, we tried to make probe-fluorescence reflect the content of alpha satellite DNA on each chromosome more exactly, using a DNA probe amplified by polymerase chain reaction.

\section{INTRODUCTION}

The chromosome aberrations by irradiation of ionizing radiation are seen as acentric fragments, which are caused by chromosomal break, and dicentrics, which are caused by fusion of broken fragments. Ring chromosomes are also made at a similar frequency.

By measuring the frequency of appearance of these aberrations, we could estimate irradiation doses. The dicentric chromosome has been counted by a conventional chromosome banding method for the evaluation of dose of ionizing radiation. However, there was a difficulty in distinction of a dicentric chromosome from that with a twisted arm. Thus it is

刍岡洋祐, 平田 誠, 後藤英介, 鄧 礼容, 前川秀彰, 僑本雄之 :

国立予防衛生研究所，東京都品川区上大崎2-10-35 
medically important to quantify radiation-induced chromosome aberrations by a more accurate and automatical method for an estimate of dose in person having over-exposure to ionizing radiation.

The centric regions of human chromosomes contain a heterogenous mixture of highly repetitive DNA sequence families. Among those, alpha satellite (alphoid) DNA, dominate at the centromeres of all human chromosomes and clones of repeated monomer or higher order repeat units have been isolated from almost all types of human chromosomes ${ }^{11}$. The alpha satellite DNA repeat units consist of diverse, tandem reiterated monomer units of $\sim 171 \mathrm{bp}$, which in turn are composing various higher order repeat units of $2-3 \mathbf{k b}^{2-5}$. The units are tandemly repeated more than 1,000 times to form a long array at the centromeric regions of chromosomes. Despite a certain degree of sequence heterogeneity among the repeat units, the consensus sequences for the monomer unit were deduced from the sequence data of total 298 monomer units isolated more than 12 human chromosome types ${ }^{2,4)}$.

The availability of chromosome-specific repetitive DNA markers would provide a useful method to identify a certain type of chromosomes or chromosomal regions ${ }^{6}$. In fact, the alpha satellite DNA clones have been used for the identification of chromosomes sorted by flow cytometry and for cytogenetical analysis of human chromosomes in metaphase or even interphase cells ${ }^{7,8)}$.

Here we tried to develop a DNA probe recognizing the centrometric regions of all types of human chromosomes by fluorescent in situ hybridization (FISH) and device a system to quantify the amount of probe fluorescence hybridization on each chromosome for an estimate of radiation doses.

\section{MATERIALS AND METHODS}

The approach for generating a sequence synthetically for human alpha satellite consensus sequence was reported elsewhere ${ }^{9}$. After construction of a pUC vector DNA harboring the monomer unit DNA, plasmids carrying dimeric (pAP-2) and tetrameric (pAP-4) units were also constructed.

FISH was carried out essentially according to Pinkel et al. ${ }^{10)}$. Metaphase cells were obtained from phytohemagglutinin (PHA)-stimulated human male lymphocytes. The irradiation of $\gamma$-ray to peripheral blood lymphocytes with ${ }^{60} \mathrm{Co}$ was done after bleeding at a dose of 1 , 2 , or 4 Gy prior to PHA stimulation. When the clone of alpha monomer unit is used, pAP-4 DNA was digested with HaeIII and labeled with photoprobe ${ }^{\mathrm{TM}}$ biotin (Vector Laboratories Inc, USA) according to the manufacturer's directions. The metaphase chromosomes were denatured in $70 \%$ formamide, $2 \times \mathrm{SSC}(0.15 \mathrm{M} \mathrm{NaCl}, 0.015 \mathrm{M}$ sodium citrate $)$ at $70^{\circ} \mathrm{C}$ for $2 \mathrm{~min}$, followed by dehydration in ethanol series of increasing concentration $(50,75,95$ and 100\%) at $4^{\circ} \mathrm{C}$. The hybridization mixture contained $20 \sim 100 \mathrm{ng} / \mathrm{ml}$ biotinylated alphoid monomerDNA, $200 \mu \mathrm{g} / \mathrm{ml}$ sonicated salmon sperm DNA, $10 \%$ dextran sulfate, and $2 \times \mathrm{SSCP}(\mathrm{SSC}+15 \mathrm{mM} \mathrm{Na}$ phosphate) in $20 \sim 50 \%$ formamide at $\mathrm{pH} 7$.

After overnight hybridization at $37^{\circ} \mathrm{C}$, the slides were washed 3 times for 3 min each in $20 \sim$ 
$50 \%$ formamide, $2 \times \mathrm{SSC}$ at $42^{\circ} \mathrm{C}$, followed by 3 washes for $3 \mathrm{~min}$ each in $2 \times \mathrm{SSC}$ at $42^{\circ} \mathrm{C}$. The slides were then incubated with anti-biotin rabbit IgG, subsequently with FITC (fluorescein isothiocyanate) conjugated anti-rabbit IgG goat serum (Cappel, U.S.A.) and further with FITC conjugated anti-goat IgG rabbit serum (Cappel, U.S.A.). This cycle was repeated twice. Finally, the metaphase chromosomes were counter-stained with propidium iodide (PI; $0.8 \mu \mathrm{g}$ / $\mathrm{ml}$ ) and/or diamidinophenylindole (DAPI; $0.4 \mu \mathrm{g} / \mathrm{ml}$ ) to allow simultaneous observation of chromosomes and hybridized probe-fluorescence. The slides were mounted with $50 \%$ glycerol in phosphate buffered saline supplemented with antifade solution and screened with Nikon fluorescence microscope. Fluorescence intensities were measured by using a fluorescence digital image microscope equipped with a high gain colour CCD (charge coupled device) camera

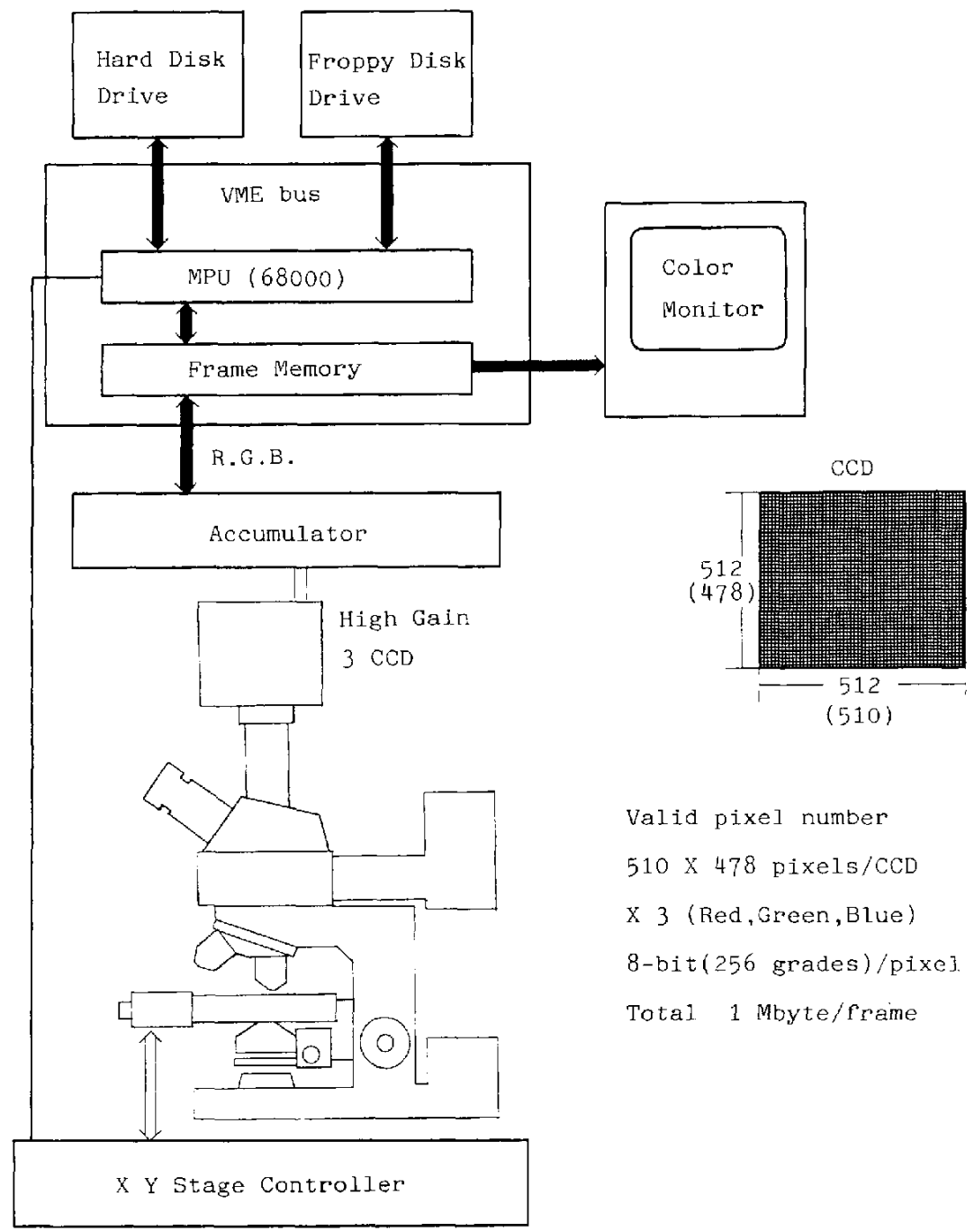

Fig. 1. Fluorescence microscope digital image analysis system. 
(Flovel, HCC-3600) controlled by a generator (Fig. 1). Fluorescence image was transferred to a digital image processor. Integration of the intensity of an image was performed by a VME system using the software developed by us. Fluorescent images observed in the microscope were stored tentatively in the accumulator, and then transferred to frame-memory.

Then the following processes were performed as shown in Fig. 2. First, fluorescence on chromosomes were stored and other background fluorescence were removed. Second, determination of each chromosome area; if two or more chromosomes crossed together, each chromosome area were settled to be separately measured. Third, fluorescence by the hybridized probes were surrounded to be measured. Then, the amount of red fluorescence on each chromosome was integrated as total chromosomal DNA amount. While, the green fluoresc-
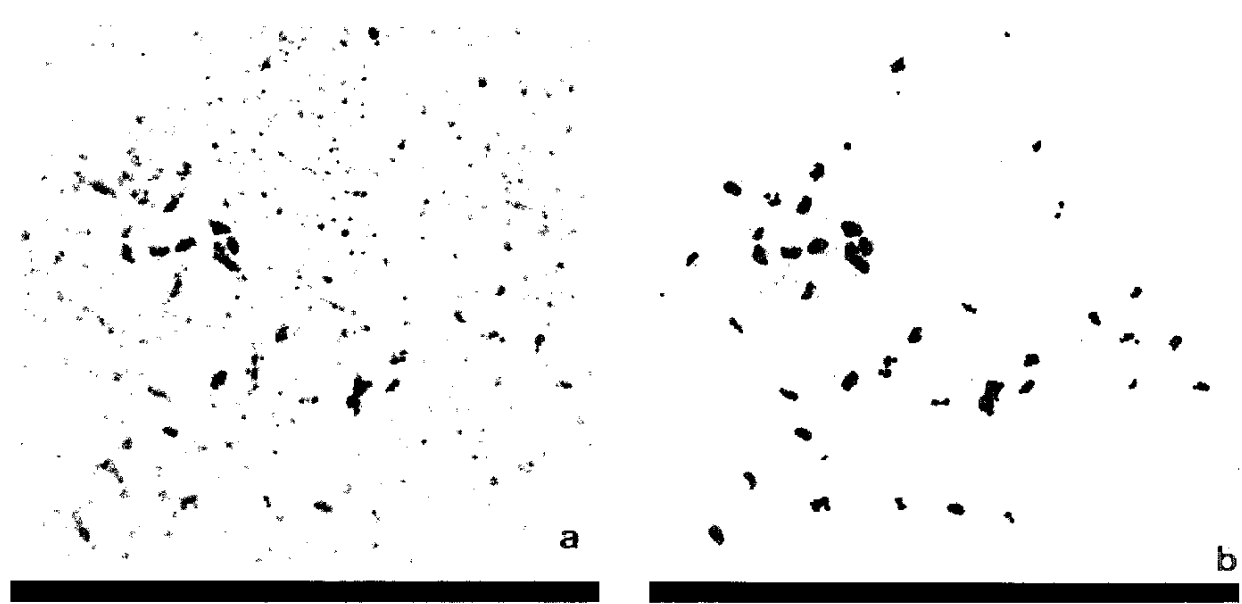

\section{b}

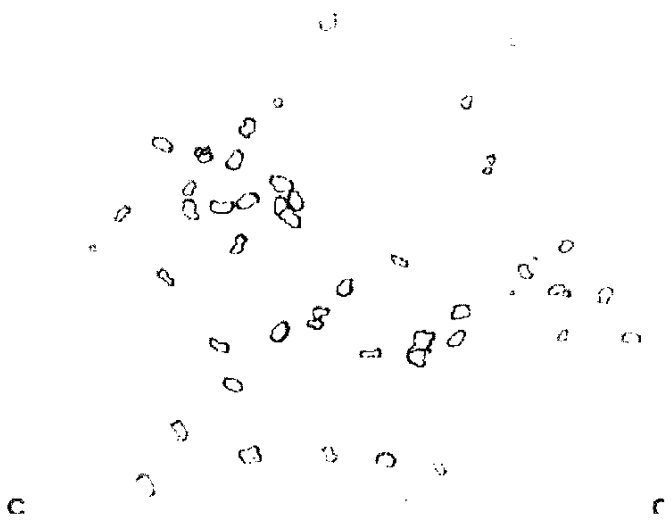

Fig. 2. Process of fluorescent image.

a) fluorescence image through colour CCD camera,

b) removal of background fluorescence,

c) determination of each chromosome area,

d) determination of probe-hybridized area. 
ence (FITC) on the chromosomes were integrated and indicated as percentage of total green fluorescence on 46 chromosomes in one metaphase.

Polymerase chain reaction (PCR) was performed for an amplification of alpha satellite DNA probe. PCR was carried out according to the manufacturer's direction (Perkin-Elmer/ Cetus) with $1 \mu \mathrm{g}$ of human genome DNA, and $2.5 \mu \mathrm{M}$ of each primer, for 30 cycles of $94^{\circ} \mathrm{C}$-denaturation $(30 \mathrm{sec}), 41^{\circ} \mathrm{C}$-annealing $(1 \mathrm{~min})$, and $72^{\circ} \mathrm{C}$-extention $(1.5 \mathrm{~min})$ in an automated thermal cycler (Perkin-Elmer/Cetus, U.S.A.) The primer sequences containing CENP-B (centromere antigen $B$ ) box ${ }^{11)}$ are as follows: $5^{\prime}$ CCAACGAAATCCTCAGAGAG 3', 5' AAACGGGATAATCTTCAC 3; where underlined sequences are CENP-B box.

\section{RESULTS AND DISCUSSION}

We showed that all centromeric regions of human chromosomes were labeled with FITC sufficiently by FISH under a lower stringency condition ${ }^{9)}$. We also found that the probe could detect both centromeric regions in a constitutional dicentric $\mathrm{X}$ chromosome ${ }^{9}$.

Thus we tried to use the synthetic alphoid DNA probe for a measurement of dicentrics in metaphase of radiation-exposed cells.

Using the alphoid probe, we showed several dicentrics (stained with FITC) as well as acentric fragmented chromosomes in metaphases of $\gamma$-irradiated cells and that the number of appearance of dicentrics or acentric fragments seemed to be proportional to radiation doses ${ }^{12)}$. To make such examinations with a certain number of chromosomes of metaphase, a quantitative fluorescence measurement was performed using a fluorescence microscope digital image analysis system.

A linear relationship appeared between total PI fluorescence on each chromosome and the chromosome area surrounded as fluorescent image, that is corresponding to chromosome size. This resembles a dot plot of chromosomal fluorescence versus intensitites of scattered light by flow cytometry.

While, as shown in Fig. 3, plots of relative amounts of probe-fluorescence (percent of total FITC in one metaphase) varies to a certain extent (between 1 to $4 \%$ ) with chromosomes indicated as relative PI fluorescence.

These differences might be partly due to inadequate reflection of consensus sequence from real construction of alphoid monomer units on each chromosome and a polymorphism in satellite DNA content even with homologous chromosomes. However, as shown in Fig. 4, we could score dicentrics and acentric fragments as dots with extraordinarily higher or low percentage in plots of relative amount of FITC on chromosomes in metaphases of $\gamma$-irradiated cells, compared to the dots of unirradiated cells. The dots were accumulated from the data of 10 metaphases.

Figure 5 is a dose-response curve based on the data shown in Fig. 4. The number of appearance of acentric fragments are proportional to the doses of $\gamma$-irradiation of 1,2 , and $4 \mathrm{~Gy}$, suggesting a first order relationship. In the case of dicentrics, including multi-centrics, a linear-quadratic increase appeared with increasing doses. Since dicentrics are considered to be 


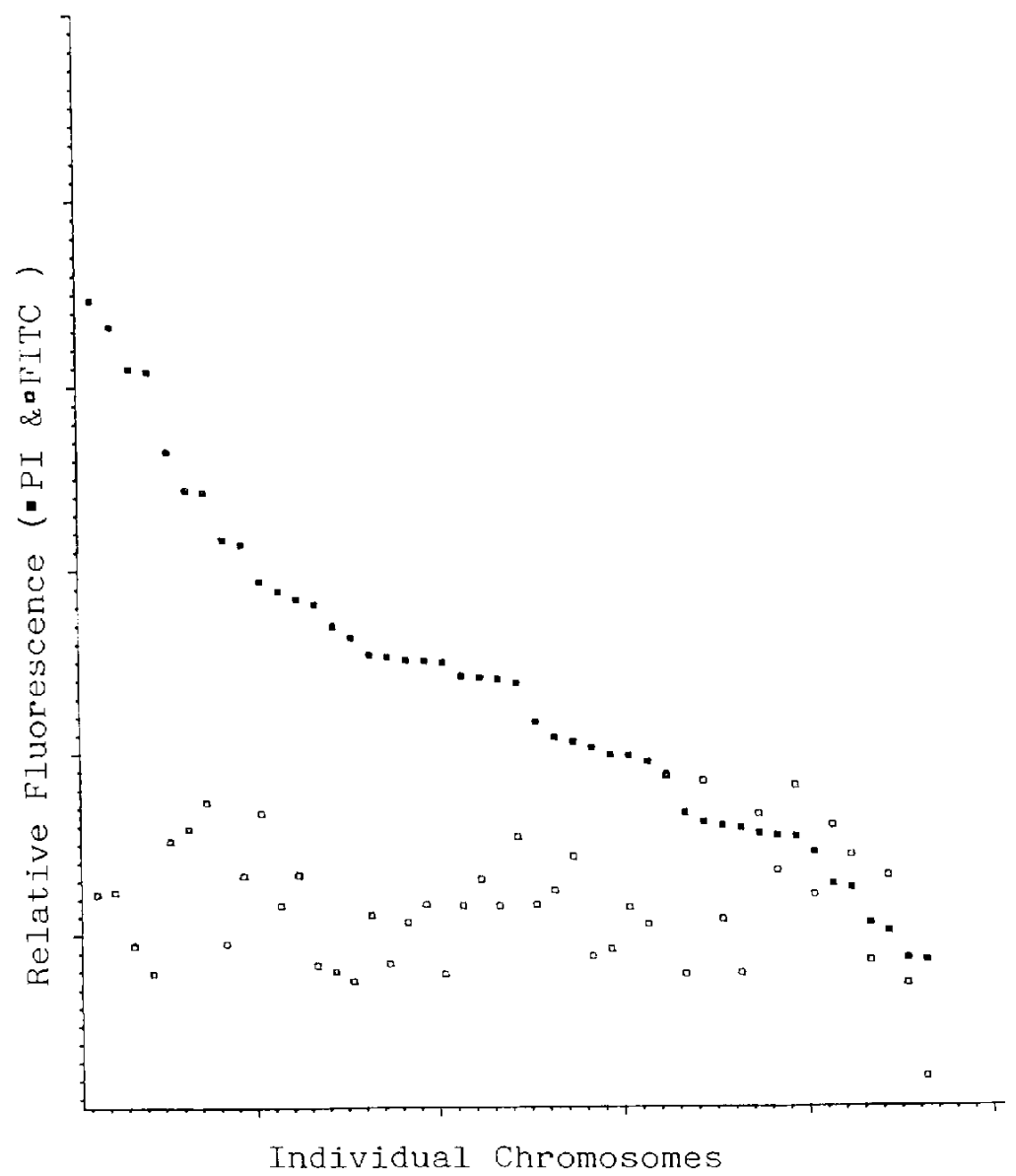

Fig. 3. Plot of relative amount of probe-fluorescence versus relative PI fluorescence on each chromosome.

——; PI fluorescence, ——-; FITC fluorescence

formed as a result of dual radiation action, the result would be reasonable.

However, some ambiguity remained especially at a lower dose, so we tried to device a system to find out a chromosome with a higher percentage of probe-fluorescence in total on two separate centromeres by scanning intensity along the axis of chromosome.

Since we have to search a large number of metaphases to find out dicentrics at lower doses, we tried to develop an alphoid DNA probe minimizing variation of probe-fluorescence with chromosomes so that we could simply score dicentric dots with a higher percentage of probe-fluorescence than the highest value of unirradiated cell metaphase chromosomes.

The alpha satellite DNA contain a motif of $17 \mathrm{bp}$, called CENP-B box, which was found to bind to one of centromere antigen, CENP-B protein ${ }^{11)}$. The motifs are present periodically in various subclasses of alpha satellite DNA of all human chromosome types except $Y$. Using the 17 bp sequence as a primer for PCR amplification, we could expect to obtain alphoid DNA 


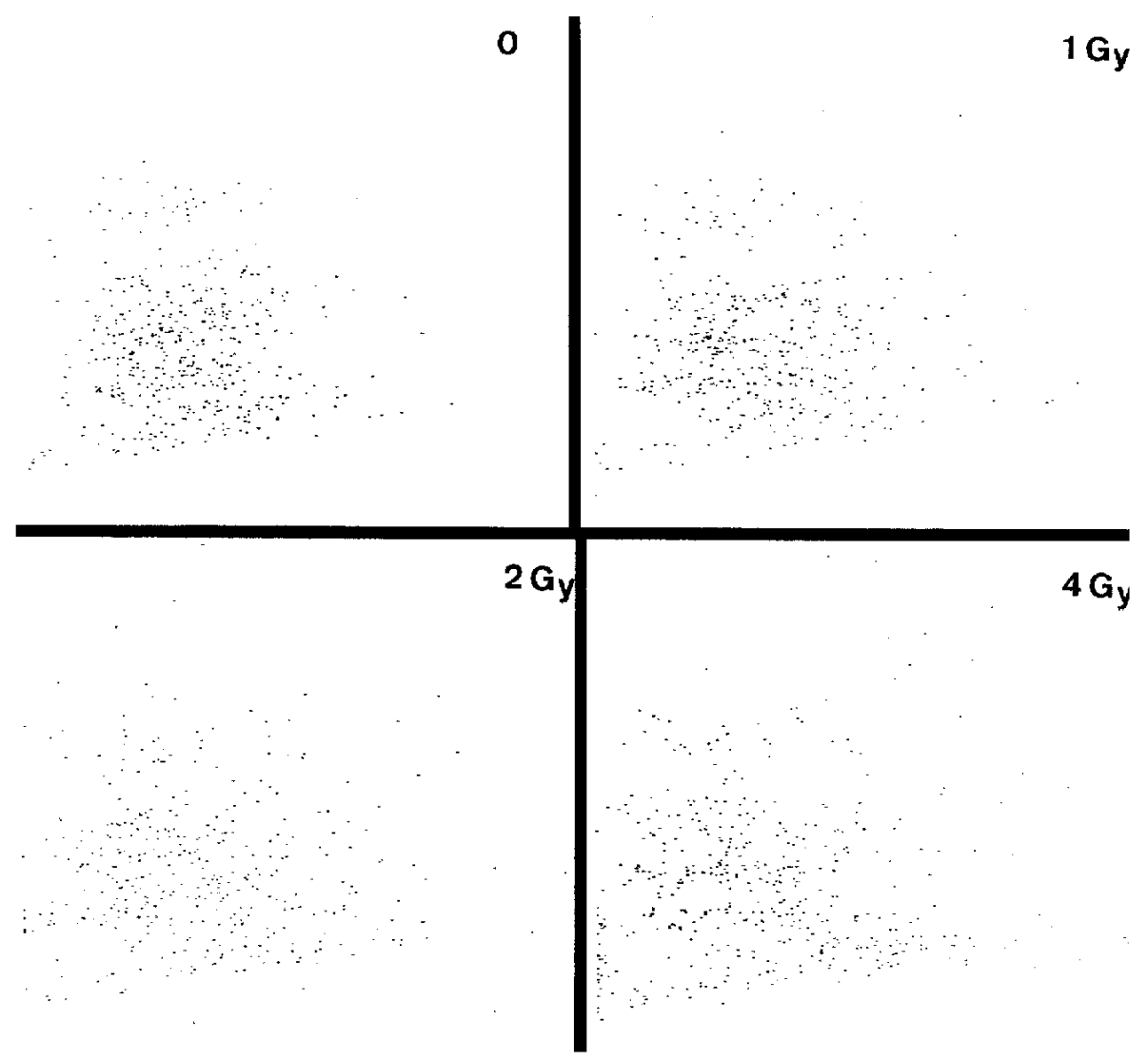

Fig. 4. Distribution of relative amounts of probe-fluorescence on chromosomes in metaphase of $\gamma$-irradiated cells.

o) unirradiated cells; cells irradiated with $1 \mathrm{~Gy}$ ), $2 \mathrm{~Gy}$ ), and $4 \mathrm{~Gy}$ ).

The dots were accumulation from the data of 10 metaphases.
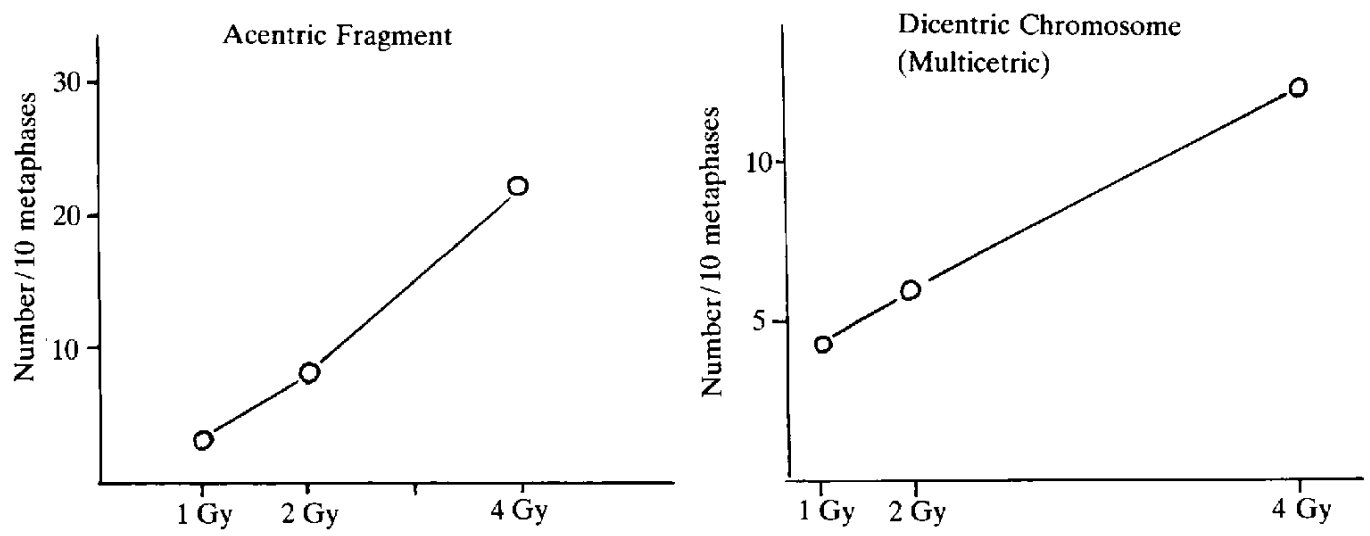

Fig. 5. Dose-response curve of the appearance of acentric fragments and dicentrics. 
reflecting the higher order repeat units of various chromosomes more exactly.

Main products amplified between CENP-B box sequence by PCR were about 510 bp and 340 bp (less amount) DNA fragments. Using the product as a probe, we performed FISH with unirradiated lymphocyte cell metaphases. Fig. 6 shows dot plots of relative amounts of probefluorescence versus chromosome sizes.

The variation of probe-fluorescence with CENP-B box primed PCR product as a probe (Fig. 6b) was reduced by about one fifth, compared to that with the consensus alphoid DNA as a probe (Fig. 6a).

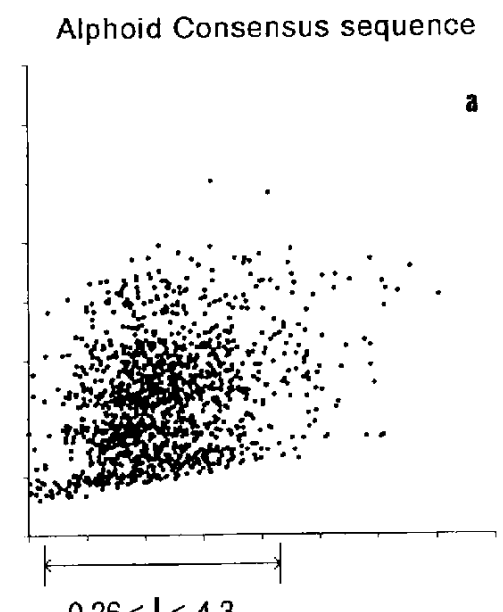

$0.26<1<4.3$
CENP-B box primed PCR product

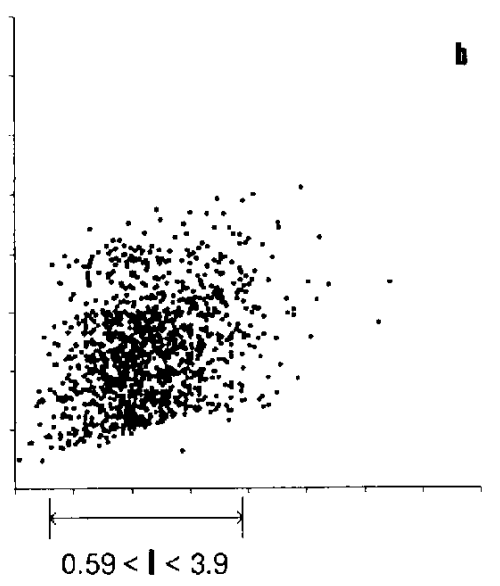

1 : interval for including $95 \%$ of population

Fig. 6. Plots of relative amounts of probe-fluorescence on chromosomes versus chromosome sizes.

a) using synthesized consensus DNA unit as a probe,

b) using CENP-B box primed PCR product as a probe.

The intervals for including $95 \%$ population (indicated as bars) were caliculated according to the formula.

However, there remains a difficulty to score di-and multi-centrics simply as dots with a percentage higher than the upper limit of the interval for including $95 \%$ population of untreated cell metaphase chromosomes.

Anyhow, although acentric and most dicentric chromosomes are not inheritable, scoring of such chromosomes could be used as a measuring system for radiation doses just after exposure. Furthermore, using the synthetic alpha satellite DNA and the measuring system, we could analyze chromosome abnormalities such as stable dicentrics and centromere-involved chromosome translocation. 


\section{ACKNOWLEGEMENT}

This work was supported by a grant of the project on Assessment and Reduction of Radiation Risks supported by Science and Technology Agency of Japan.

\section{REFERENCES}

1. Kidd, K. K., Bowcock, A. M., Schmidtke, J., Track, R. K., Ricciuti, F., Hutchings, G., Bale, A., Pearson, P., and Willard, H. F. (1989) Report on the DNA committee and catalogs of cloned and mapped genes and DNA polymorphisms. Cytogenet. Cell Genet. 51: 622-947.

2. Waye, J. S., and Willard, H. F. (1987) Nucleotide sequence heterogeneity of alpha satellite repetitive DNA: a survey of alphoid sequences from different human chromosomes. Nucl. Acids Res. 15: 7549_ 7569.

3. Alexandrov, I. A., Mitkevich, S. P., Yurov, Y. B. (1988) The phylogeny of human chromosome specific alpha satellites. Chromosoma 96: 443-453.

4. Vissel, B, Choo, K. H. (1987) Human alpha satellite DNA-consensus sequence and conserved regions. Nucl. Acids Res. 15: 6751-6752.

5. Willard, H. F., Waye, J. S. (1987) Chromosome-specific subsets of human alpha satellite DNA: analysis of sequence divergence within and between chromosomal subsets and evidence of an ancestral pentameric repeat. J. Mol. Evol. 25: 207-214.

6. Moyzis, R. K., Albright, K. L., Bartholdi, M. F., Cram, L. S., Deaven, L. L., Hilderbrand, C. E., Joste, N. E., longmire, J. L., Meyne, J., Robinson, T. S. (1987) Human chromosome-specific repetitive DNA sequences: novel markers for genetic analysis. Chromosoma 95: 375-386.

7. van Dekken, H., Bauman, J. G. J. (1988) A new application of in situ hybridization: detection of numerical and structural chromosome aberrations with a combination centromeric-telomeric DNA probe. Cytogenet. Cell Genet. 28: 188-189.

8. Dale, S., Earle, E., Voullaire, L., Rogers, J., Choo, K. H. (1989) Centromeric alpha satellite DNA amplification and translocation in an unusually large chromosomes $14 \mathrm{p}^{+}$variant. Hum. Genet. 82: 154158.

9. Kameoka, Y., Date, T., Hashimoto, K. (1990) Application of synthetic DNA probes of human alpha satellite consensus monomer for detection of centromere- involved chromosome abnormalities. Jpn. J. Human Genet. 35: 227-233.

10. Pinkel, D., Straume, T., Gray, J. W. (1986) Cytogenetic analysis using quantitative, high-sensitivity, fluorescence hybridization. Proc. Natl. Acad. Sci USA 83: 2934-2938.

11. Masumoto, H., Masukata, H., Muro, Y., Nozaki, N., and Okazaki, T. (1989) A human centromere antigen (CENP-B) interacts with a short specific sequence in alphoid DNA, a human centromeric satellite. J. Cell Biol. 109: 1963-1973.

12. Kameoka, Y., Hirata, M., Kusuda, J., Date, T., and Hashimoto, K. (1991) Human chromosome analysis using synthetic repetitive DNA units as a fluorescent probe. Proceedings of the International Symposium on Flow Cytometry and Image Analysis for Clinical Applications, Morioka, Japan, 1-3 July 1990. pp. 53-58, International Congress Series No. 933, Elsevier Science Publishers 1991. 